\title{
La lucha por la vida con xeroderma pigmentoso en la mansión de Los otros (2001)
}

\author{
Esteban AGUILAR-VARGAS, Víctor Manuel AYUSO-DIAZ, Nina Isabel MÉNDEZ-DOMÍNGUEZ \\ Universidad Marista de Mérida, Yucatán, México. \\ Autor para correspondencia: Esteban Aguilar-Vargas. Correo electrónico: esteban.aguilar.vargass@gmail.com \\ Recibido el 9 de julio de 2018; aceptado el 13 de septiembre de 2018.
}

Cómo citar este artículo: Aguilar Vargas E, Ayuso Diaz VM, Méndez Domínguez NI. La lucha por la vida con xeroderma pigmentoso en la mansión de Los otros (2001). Rev Med Cine [Internet] 2019;15(2): 81-8.

DOI: http://dx.doi.org/10.14201/rmc20191528188

\begin{abstract}
Resumen
En la práctica médica nos encontramos día a día con pacientes que cursan con alergias o reacciones atípicas a elementos que se encuentran de manera común a su alrededor, pero en pocas ocasiones hemos de toparnos con reacciones tan severas como las que caracterizan a los individuos que padecen xenoderna pigmentoso. En la película Los otros (2001) de Alejandro Amenábar, los espectadores somos testigos de la lucha constante por la vida y por la salud que Grace enfrenta diariamente, una lucha contra el efecto de nada menos, que el sol mismo. La trama nos permite sentir la ansiedad, el estrés y la frustración que caracteriza a los habitantes de la mansión, ante una situación que finalmente, se resolvería de manera definitiva con el alto costo de su propia vida. Finalmente, la muerte resultó ser para los habitantes, una vía reveladora y liberadora que les permite recobrar la alegría y tranquilidad.
\end{abstract}

Palabras clave: dermatología, hipersensibilidad, rayos ultravioleta, xeroderma pigmentoso.

\section{A fight for life with xeroderma pigmentosum at The others (2001) mansion}

\begin{abstract}
Summary
During our medical practice we can find patients that have allergies or atypical reactions to elements that are commonly seen around them, but sometimes we can find severe atypical reactions like the lesions that characterizes the xenoderma pigmentosum. The others (2001), film written and directed by Alejandro Amenábar, makes us witnesses of the struggle and constant battle of Grace for keeping their children healthy against the effect of the sun. The plot allows us to feel the anxiety, stress and frustration that characterizes the inhabitants of the mansion, before a situation that finally, was ultimately resoluted with the high cost, their own life. Finally, death turned out to be for the inhabitants, a revealing and liberating way that allows them to recover joy and serenity.
\end{abstract}

Keywords: Dermatology, Hypersensitivity, Ultraviolet Rays, Xeroderma Pigmentosum. 


\section{Ficha técnica}

Título: Los otros.

Título original: The others.

País: España, Estados Unidos, Francia, Italia.

Año: 2001.

Director: Alejandro Amenábar.

Música: Alejandro Amenábar.

Fotografía: Javier Aguirresabore.

Montaje: Nacho Ruiz Capillas.

Guion: Alejandro Amenábar.

Intérpretes: Nicole Kidman, Fionnula Flanagan, Christopher Eccleston, Alakina Mann, James Bentley, Eric Sykes, Elaine Cassidy, Renée Asherson, Gordon Reid, Keith Allen, Michelle Fairley, Alexander Vince, Ricardo López y Aldo Grillo.

Color: color.

Duración: 104 minutos.

Género: terror, misterio, thriller.

Sinopsis: "Isla de Jersey, 1945. La Segunda Guerra Mundial ha terminado, pero el marido de Grace (Nicole Kidman) no vuelve. Sola en un aislado caserón victoriano de la isla de Jersey, educa a sus hijos dentro de rígidas normas religiosas. Los niños sufren una extraña enfermedad: no pueden recibir directamente la luz del día. Los tres nuevos sirvientes que se incorporan a la vida familiar deben aprender una regla vital: la casa estará siempre en penumbra, y nunca se abrirá una puerta si no se ha cerrado la anterior. Pero el estricto orden que Grace ha impuesto se verá desafiado por circunstancias que escapan a su control"(FilmAffinity).

Premios: Premios Oscar: Nominada a mejor actuación a Nicole Kidman, Golden Globes (2002), a mejor película BAFTA (2002), a mejor actuación de actriz principal BFTA (2002), nominada a mejor director y escritor, y ganadora del Saturn Awar a mejor película de terror, mejor a Nicole Kidman y mejor actriz de reparto a Fionnula Flanagan en los Academy of Science Fiction, Fantasy \& Horror Films (2002), nominado por mejor película en los ALMA Awards (2002), ganadora del premio ASCAP (2002)...

Productora: Cruise-Wagner Productions, Sogecine, Las Producciones del Escorpión,
Dimension Films, Canal+ España, Lucky Red, Miramax.

\section{Enlaces:}

https://www.imdb.com/title/tt0230600

https://www.filmaffinity.com/es/film370368.html

\section{Trailer en español}

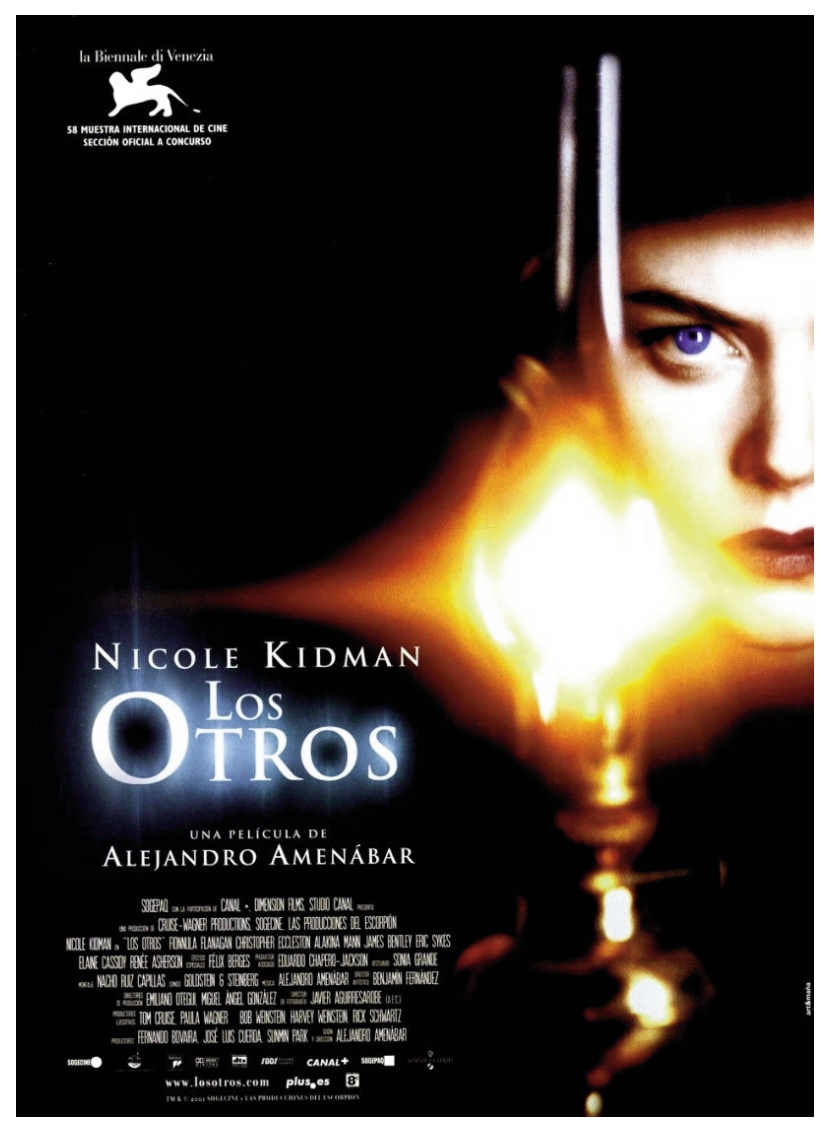

Introducción

Los otros (2001), película Alejandro Amenábar que, a pesar de centrarse en misterios enigmáticos de lo paranormal, nos permite realizar el análisis de algunas directrices no profundizadas en el filme. Dentro de estas podemos identificar a los hijos de la protagonista, quienes, continuamente viviendo en la reclusión fundamentada de su madre Grace Stewart (Nicole Kidman), viven en el confinamiento de la oscuridad de su hogar.

Durante la trama, de inicio a fin, podemos darnos cuenta como Grace, representa una imagen de autoridad y protección para sus hijos. Al llegar inicialmente los 
nuevos sirvientes, y antes de presentarle a sus hijos, Grace pide a Lydia (Elaine Cassidy) (una de las nuevas mucamas) retirarse a la cocina y cerrar todas las cortinas de las ventanas de la casa, esto para poder presentarle a sus hijos sin riesgo alguno (Fotos 1, 2 y 3), siempre condecorada con el lema "En esta casa ninguna puerta puede abrirse, sin cerrar primero la anterior" (Foto 4 y 5 ). Al aproximarse a las penumbras de los cuartos de sus hijos, Grace enciende un candil a bajo fuego, expresando que esa era la máxima luz dispuesta a la que pudiesen enfrentarse sus hijos sin causarles algún daño, debido a

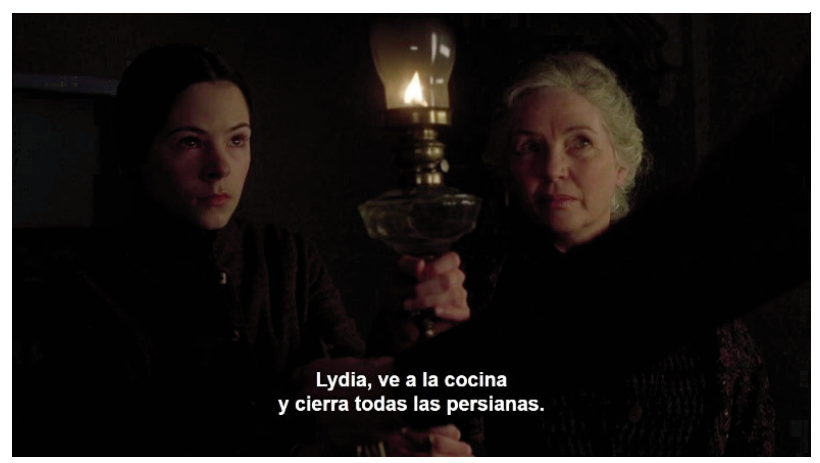

Foto 1. Presentación con los niños: ordenes de cerrar las cortinas.

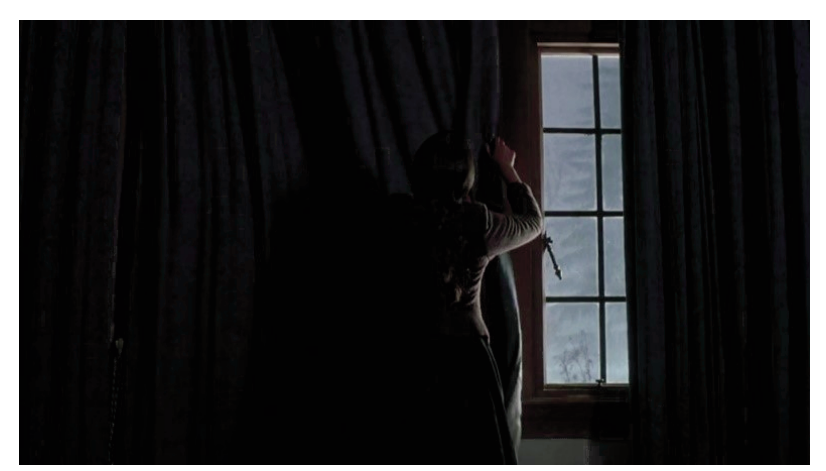

Foto 2. Presentación con los niños: cierre de las cortinas.

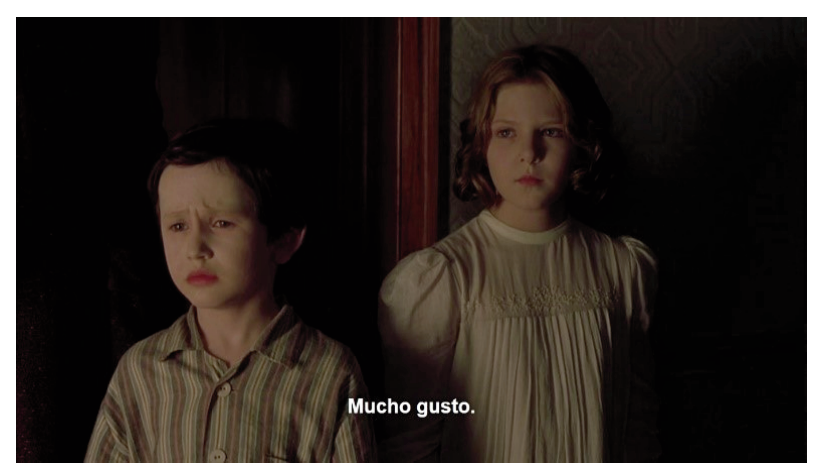

Foto 3. Presentación con los niños: el primer encuentro con los nuevos sirvientes.

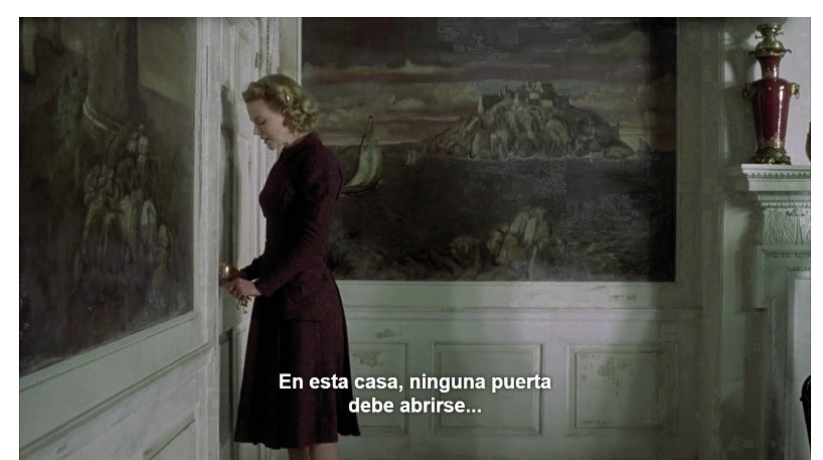

Foto 4. Lema de Grace: Advertencia para la protección parte 1.

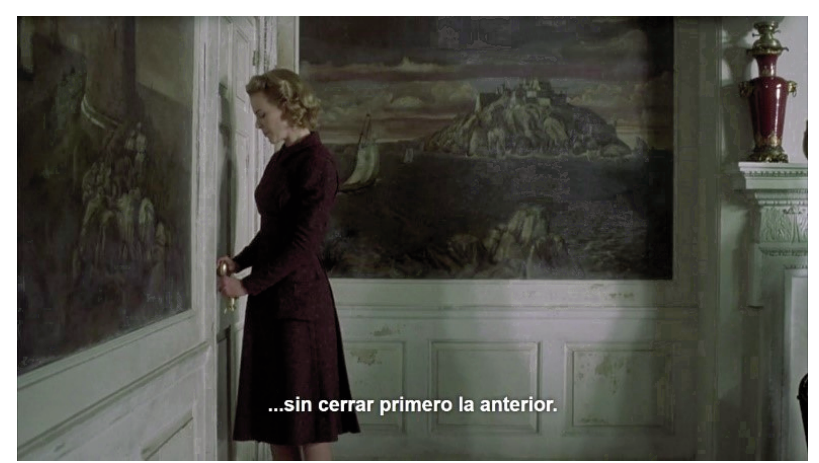

Foto 5. Lema de Grace: Advertencia para la protección parte 2.

que, como Grace refiere a los nuevos sirvientes de la casa, presentan una alteración a la cual "Los médicos nunca encontraron la cura" (Foto 6), siendo fotosensibles a los rayos UV que, "Eventualmente sería fatal".

Grace manifestó al inicio del filme que lesiones se asemejan a las llagas y ampollas, que eventualmente, empiezan a ahogar a sus hijos y que potencialmente, pudiera ser fatal para ellos. Dentro del espectro de la dermatología podemos identificar sin número de patologías que eventualmente en la actualidad, gracias al avance

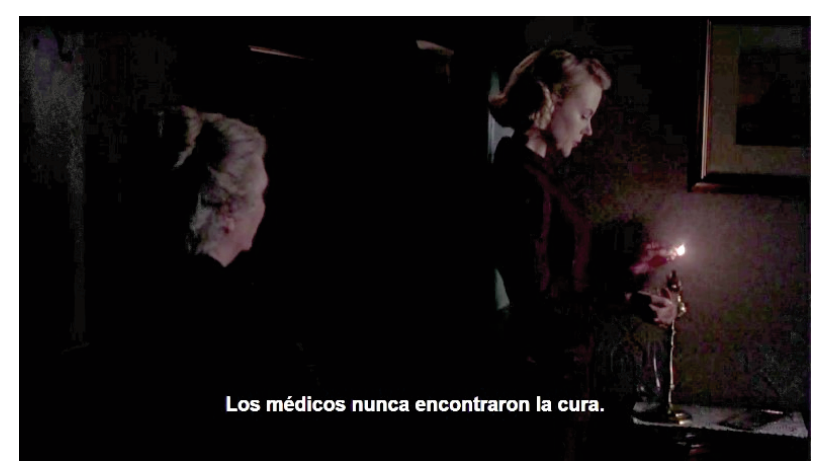

Foto 6. Explicación de la condición de sus hijos. 
tecnológico y los nuevos procedimientos diagnósticos, podemos identificar y secundariamente tratar, sin embargo, muchas de estas patologías a priori pueden simular a los múltiples diagnósticos diferenciales de las lesiones máculo-papulares y ampollosas como describe inicialmente la protagonista, generando en el médico un digno reto diagnóstico. En el presente artículo revisaremos las principales características clínicas, diagnóstico y tratamiento del xeroderma pigmentoso, así como el diagnóstico diferencial de las reacciones fotosensibles.

\section{Definición}

El xenoderma pigmentoso es una rara enfermedad la cual se transmite de una forma autosómica recesiva, su diagnóstico es clínico y cuya predicción es funesta. La enfermedad está íntimamente ligada a defectos sobre la reparación del DNA celular, el cual se encuentra dañado por efectos fotosolares, dando como resultado de la acumulación de productos oncogénicos aunado a una inhibición de genes supresores del crecimiento tumoral. Destaca entre las manifestaciones de esta enfermedad lesiones del espectro cutáneo, ocular y neurológicas degenerativas las cuales se dan a manifiesto desde una temprana edad ${ }^{1}$.

Los resultados de los estudios clínicos de la dermis de los pacientes con xenoderma pigmentoso demuestran en términos generales que dichos pacientes sufren una fatiga de la inmunidad generada por las células de Langerhans esto ligado a la radiación ultravioleta (UV). Al igual se percibe una respuesta cutánea deteriorada sobre los antígenos de memoria, diminución marcada de células $T$-helper y una producción excesiva del interferón en linfocitos, además de una baja producción de células killer².

En el tiempo en el cual se desarrolla la película, no había aun la posibilidad de tratar los ventanales con

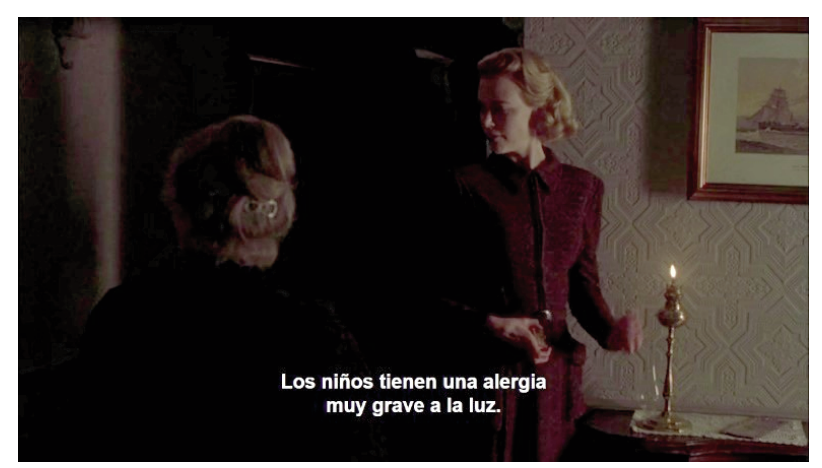

Foto 7. Advertencia de la "alergia de sus hijos". películas con filtro UV (que fueron patentados en 1961 en Los Estados Unidos), por lo cual, las personas que padecían esta rara enfermedad debían permanecer protegidos de la luz solar. De hecho, incluso a las horas del día en las cuales decae la luminosidad, aún es posible estar expuestos a los rayos UV, debido a que tanto la luz ultravioleta como la infrarroja se encuentran fuera del espectro de la luz visible ${ }^{3,4}$.

Los hijos de Grace podían presentar sin duda, aunado a la xeroderma, dato de déficit de vitamina $D$ y retraso del crecimiento, debido a que el ser humano requiere la luz solar para satisfacer los requerimientos de colecalciferol${ }^{5}$.

Adicionalmente, el fotoperiodismo y el ritmo circadiano sol elementales en la etapa de crecimiento para poder tener un funcionamiento endocrinológico óptimo, principalmente porque la hormona del crecimiento se depende del sueño nocturno y posiblemente también de la oscuridad durante el sueño, hábito que no era parte de la rutina diaria de los habitantes de la mansión de Grace ${ }^{6}$.

\section{Un padecimiento con origen genético}

El xenoderma pigmentoso se encuentra ligado con el defecto congénito de una endonucleasa que interfiere en la reparación del DNA de las células de la piel, las cuales mutan por la exposición de los rayos UV incluso a mínimas cantidades7. Previo a la presentación de los hijos de la protagonista a la nueva servidumbre, ella explica como sus hijos son "alérgicos a la luz del sol" lo que pudiese explicarse por origen fotosensible de la patología (Foto 7).

El origen genético de esta peculiar enfermedad se genera mediante el copiado anómalo del DNA durante sus varias divisiones celulares, este proceso tiende a sufrir varios errores. Estos errores pueden ser variados y ocasionar la avería del DNA. La célula es capaz de reconocer estos errores y repararlos tomando como referencia el modelo de la cadena complementaria la cual se encuentra sin errores, sin embargo, las mutaciones que pueden suprimir esta cualidad de la célula para repararse son las causantes del trastorno genético. Un ejemplo de este error es cuando la luz UV produce la dimerización sobre residuos de timina que se encuentran contiguos en la misma cadena de DNA, la cual causa que los nucleótidos pierdan la capacidad de aparearse con los residuos de adenina de la cadena complementaria ${ }^{8}$.

La genética de esta enfermedad es muy variada, lo cual hace que existan siete categorías $(A, B, C, D, E, F$ 
y G) y además una variante $(\mathrm{XP}-\mathrm{V})^{9}$. En el xenoderma pigmentoso se encuentran mutaciones en los genes ERCC2, ERCC3, POLH, XPA y XPC, los cuales son responsables de la reparación del DNA dañado:

Gen ERCC2: se localiza en el brazo largo del cromosoma 19 (19q13.3), Conforme la localización de al gen ERCC3 se sitúa en el brazo largo del cromosoma 2 (2q21), sus productos son las proteínas XPD y XPB, respectivamente. Estas 2 proteínas son subunidades del complejo TFIIH. Dicho complejo se encarga de 2 funciones importantes: ayudara la transcripción de genes y apoyar a la reparación del DNA dañado. La función conjunta de las dos proteínas es iniciar la transcripción de genes. Hoy en día se han descubierto 24 mutaciones en el gen ERCC2 pero solo una en el ERCC3 en personas con xenoderma pigmentoso.

El gen ERCC3 mutado cambia dentro de la proteína que codifica el aminoácido fenilalanina por serina en el lugar 99(Phe99Ser o F99S). Tanto el gen ERCC2 y ERCC3 ocasionan que el complejo TFIIH no pueda cumplir con su función de arreglar el DNA dañado de manera correcta, dando como resultado la acumulación de DNA, esta culmina en un mal funcionamiento de las células, las cuales terminan por perecer o se transforman en oncogénicas. Los padecimientos causados por la mutación de este gen se ligan con alteraciones neurológicas degenerativas.

Situado en el brazo corto del cromosoma 6 (6p21.1) se encuentra el gen POLH el cual codifica para una de las polimerasas (eta), las cuales son un grupo de enzimas encargadas de la preparación para la división celular, así como para la copia del material genético, además su función más importante es la de ayudar a la reparación del DNA. Las polimerasas eta se encargan de copiar el DNA que ha sido incorporado por los rayos de luz UV. Existen 30 mutaciones del gen POLH las cuales desencadenan la variante del xenoderma pigmentoso conocido como (XP-V); una característica de esta variante, así como la de las otras es la fotosensibilidad a los rayos UV y en comparación a esta en particular (XP-V) con las demás es que no se asocia con alteraciones neurológicas. La mutación del gen POLH hace que la polimerasa eta no se codifique lo que como resultado da un copiado de DNA dañado por parte de las células. Si no realiza su función la polimerasa, los rayos UV terminan dando errores en el DNA y estos se acumulan en los genes los cuales regulan el crecimiento y la división celular. El resultado final de los errores del DNA es un rápido crecimiento de forma descontrolada. La culminación es que las personas que padecen xenoderma pigmentoso$\checkmark$ corren mayor riesgo de desarrollar cáncer de piel en las zonas que se expongan al sol.
En el cromosoma 9 específicamente en el brazo largo (9q22.3) se encuentran los genes XPA y del brazo corto del cromosoma 3 (3p25.1) el XPC ambos codifican proteínas que se encargan para la reparación de DNA dañado. Entre las forman que usan las células para reparar el DNA se encuentra la escisión de nucleótidos, tanto la proteína XPA como la XPC ayudan a verificar el daño del DNA y a dejarlo estabilizado mediante una reparación. El material que aportan estas proteínas se unen en las zonas del DNA dañado donde juntan su función con las otras proteínas a manera complejo, este complejo se encarga de reparar cambiando el DNA afectado por uno correo. En total existen 25 mutación para el gen XPA y 40 para XPC que desencadenan xenoderma pigmentoso. Cualesquiera de estas mutaciones ocasionan que se acumule DNA dañado ocasionando que este funcione mal o induciendo que la célula se vuelva oncogénica. La mutación del gen XPA se asocia con alteraciones neurológicas degenerativas ${ }^{10}$.

Es aun imprecisa la epidemiología de este padecimiento, sobre qué tan frecuentemente afecta a los hermanos, gemelos o mellizos; pero existe en la literatura un reporte de caso en el cual se pudo evidenciar que un par de hermanos, a pesar de manifestar ambos el fenotipo enfermo, la respuesta a las intervenciones terapéuticas no fue la misma para ambos, siendo que, en uno de ellos, el tratamiento con el fármaco imiquimod alivió la formación de tumores cutáneos, a la vez que fracasó en uno de ellos. La película nos sugiere una mayor susceptibilidad ante la exposición al sol en el hermano menor que en la hermana, lo cual resulta incluso un tato similar al caso real que existe en la literatura médico-científica11.

\section{Manifestaciones clínicas}

Las manifestaciones del xenoderma pigmentoso se dan desde el final del primer año, el enrojecimiento severo, fotofobia, quemaduras de sol y ampollas son algunas de las consecuencias de la mínima exposición al sol, otras más avanzadas como descamación, exulceraciones y cambios neurológicos ${ }^{12}$.

Entre el 80 y $90 \%$ de los afectados con xenoderma pigmentoso desarrollan problemas oculares ${ }^{13}$. Entre las manifestaciones de estos se encuentran: fotofobia, lagrimeo, blefaritis, queratitis, opacidad corneal y lo más avanzado como tumores en los párpados desencadenando en ocasiones la posible ceguera. Existe lesiones bucales con malformaciones dentarias y carcinomas en un $79 \%$ de los pacientes. 
Hoy en día en la literatura se describen 3 etapas morfológicas del xenoderma pigmentoso:

Primera o eritematopigmentaria/eritematoescamosa: Consiste en la presencia de eritrema, edemas y en ciertos casos vesículas, posterior a esto se desarrollan manchas de color marrón con frecuencia estas confluyen ${ }^{14}$. Esta sintomatología permanece para toda la vida. A nivel ocular se presenta conjuntivitis y fotofobia. En algunos casos se ha encontrado la tendencia de aparición de caries de manera temprana ${ }^{8}$.

Segunda o fase atrófica/telangiectásica: En esta etapa las lesiones de adelgazamiento de la nariz, destrucción de los pabellones auriculares y microstimía se presentan, al igual que verrugosidades y queratosis actínicas (dermatoheliosis poiquilodérmica). De manera progresiva se dan a deslumbrar lesiones atróficas, con múltiples telangiectasias y cicatrices las cuales suplantan a las áreas pigmentadas. En esta segunda fase la piel se encuentra seca, escamosa y arrugada. Por eso se le adjunta el nombre de xenoderma, además existen también verrugosidades y queratosis actínicas, más que nada en las zonas expuestas al sol.

La tercera etapa es la conocida como tumoral, ya que el riesgo de cáncer se eleva demasiado.

El síndrome de Sanctis-Cacchione es la forma más grave de esta enfermedad, e incluyen trastornos neuropsiquiátricos (microcefalia, retrasomental, ataxia, coreoatetosis y cuadriparesia), sin embargo, la presentación de este síndrome es rara ${ }^{14}$.

Al inicio del filme podemos identificar como Grace, la protagonista, hace una descripción de las lesiones de sus hijos concordante con la fase eritematopigmentaria y telangectásica. Eventualmente las lesiones de la patología pudieran causar complicaciones que eventualmente serían fatal para los portadores (Fotos 8,9 y 10 ).

\section{Evolución}

La dermis es completamente como la de un individuo sano con la diferencia que en el sexto mes y el tercer año de vida empiezan a desencadenarse los primeros síntomas en el $75 \%$ de los casos. En ocasiones estos síntomas se desarrollan de manera aún más prematura. En todos los casos esta enfermedad es crónica y avanza de manera profunda por las tres fases, pero el tiempo en el cual avanza es impredecible. Las neoplastias cutáneas y oculares comienzan a aparecer normalmente en la infancia o adolescencia ${ }^{15}$

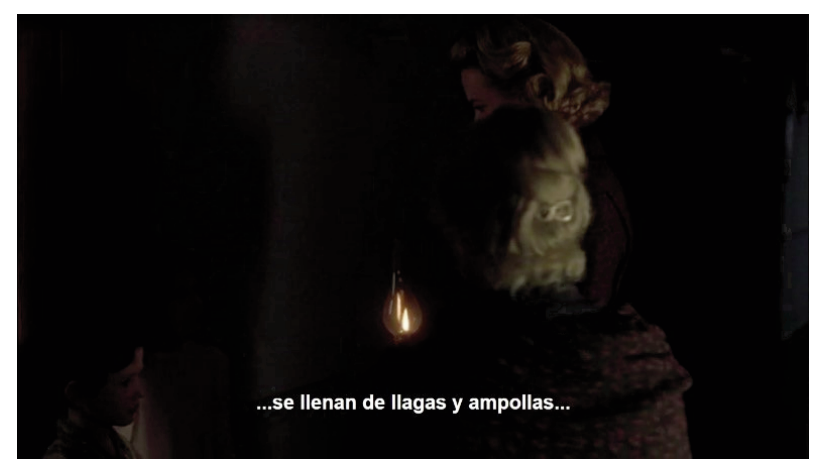

Foto 8. Descripción de las lesiones parte 1.

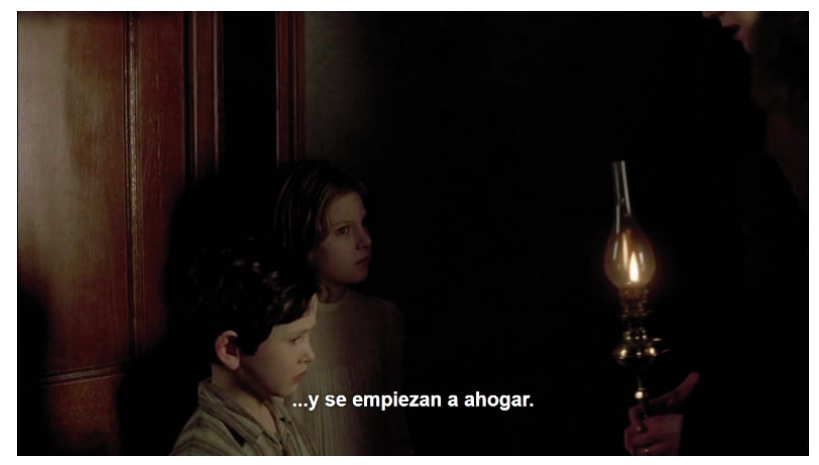

Foto 9. Descripción de las lesiones parte 2.

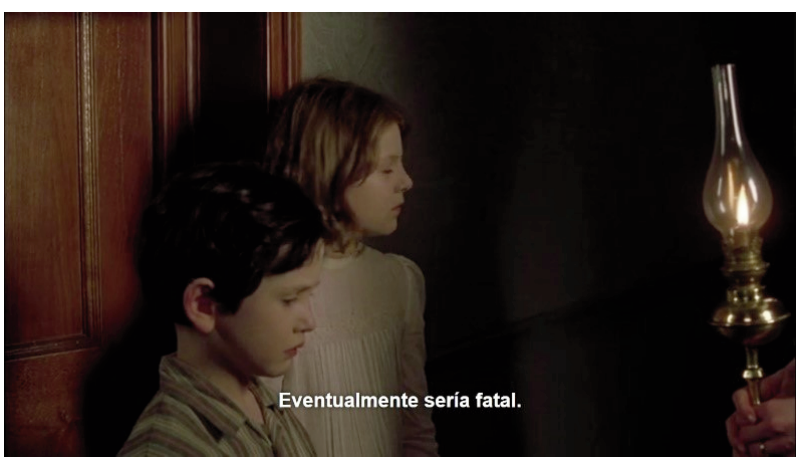

Foto 10. Descripción de las lesiones parte 3.

El cáncer de piel (CPNM) se desarrolla en la edad mediana más o menos a partir de los 8 años mientras que en las personas de la población general la media encontrada en literatura es de 60 años. Se sospecha que el principal precursor de los melanomas en las personas con xenoderma pigmentoso es el lentigo solar ${ }^{16}$.

El $66 \%$ de los pacientes con xenoderma pigmentoso fallecen antes de llegar a la adultez por los tumores cutáneos y viscerales, también influyen las complicaciones secundarias como los problemas neurológicos-infeccioso. La expectativa de vida es alrededor de los 20-30 años, sin embargo, esta cifra puede aumentar si se aplican medidas preventivas como la reducción de la exposición al sol ${ }^{8}$. 


\section{Diagnóstico diferencial}

Para esta enfermedad el diagnóstico es clínico y hoy en día, gracias a los avances de la medicina en métodos de diagnóstico se puede constatar por medio de una biopsia de las vellosidades coriónicas o por amniocentesis con base a la genética. Los diagnósticos diferenciales son otras enfermedades producidas o exacerbadas por los rayos UV o hereditarias con aumento de la hipersensiblididad celular síndrome de Cokayne, síndrome de Bloom, síndrome de Rothmun-Thompson y Progeria17.

Las quemaduras solares, la foto sensibilidad en la fase eritematosa puede simular a otras inducidas por fármacos como protoporfiria eritropoyética, erupción poliforma lumínica, porfíria congénita o enfermedad de Hartnup. De igual forma existen varias enfermedades genéticas que tienen manifestaciones de fotosensibilidad extrema por deficiencia en el sistema de reparación por escisión, dentro las más importantes encontramos a la tricotiodistrofia (TTD) ${ }^{18}$.

\section{Tratamiento}

No existe un tratamiento que erradique la enfermedad, pero un diagnóstico temprano y proteger al paciente contra los rayos UV son las pautas más importantes en el tratamiento en los pacientes con xenoderma pigmentoso. Es por ello que, aun no sabiendo la patología que atormentaba a sus hijos, Grace identificando el factor desencadenante, siempre procuró mantener su vida y la de sus hijos en las penumbras, e incluso en las situaciones dentro del filme donde pudieron sufrir agresión solar, siempre tuvo como prioridad su fotoprotección (Fotos 11 y 12).

Dentro de las medidas preventivas más importantes para la fotosensibildiad encontramos:

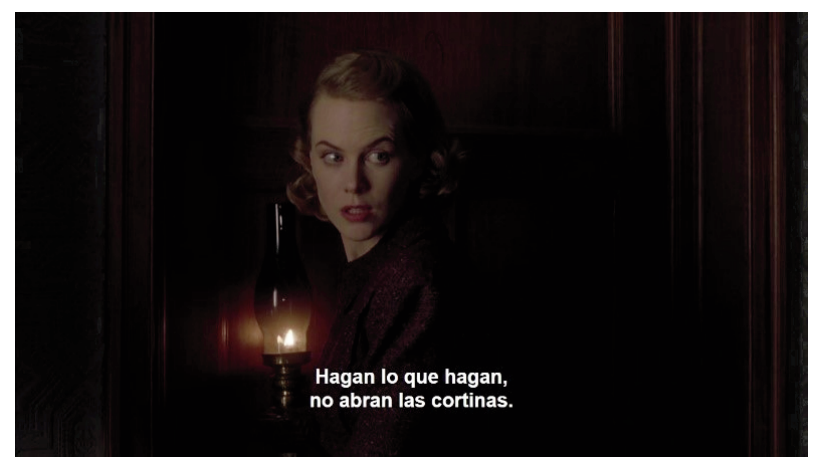

Foto 11. Advertencia de nunca abrir las cortinas.

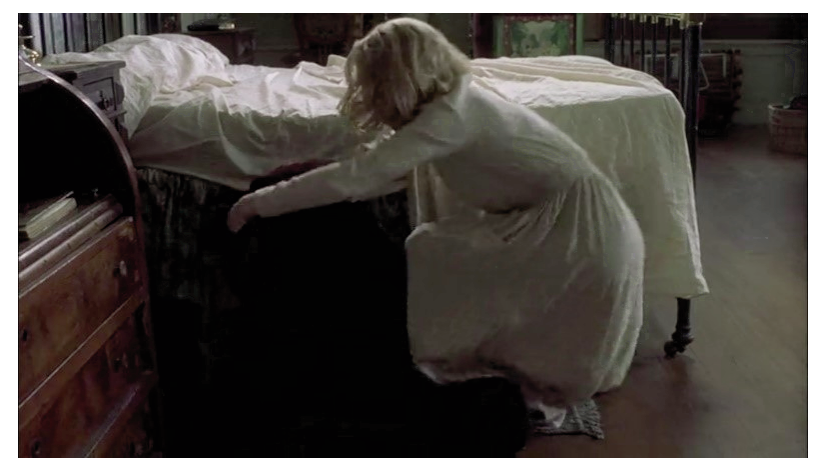

Foto 12. Intento de fotoprotección.

Cuando el paciente requiere salir se recomienda el uso de sombreros y vestimenta que cubra todo el cuerpo la cual no deje pasar los rayos UV y las zonas que no puedan estar cubiertas es necesario implementar el uso de bloqueadores de son superiores a 30 de factor de protección de preferencia cada 2 hrs. Además de evitar la sudoración.

Los globos oculares deben protegerse con el uso de lentes solares con una protección intensa contra los rayos UV.

El hogar del paciente y los medios de transporte que use deberán estar equipados con filtros contra los rayos UV.

Medidas alternas:

Extirpación quirúrgica precoz de toda lesión/tumor sospechoso.

Quimioterapia y radioterapia.

Complementos vitamínicos (especialmente vitamina $A$ y E).

Uso de retinoides tópicos y sistémicos ${ }^{8}$.

\section{Pronóstico desde la dinámica de Los otros}

Se ha podido observar en la dinámica de LoS otros, la constante lucha de una madre por mantener la salud de sus hijos. Ante una prolongada fase de negación en el duelo generado por la incurable enfermedad de sus hijos, Grace vivía en constante estrés psicoemocional, el cual era aún más pronunciado ante la ausencia del padre de familia. Tal fue el grado de negación de Grace, que no fue hasta ver las fotografías postmortem de cada uno de ellos que pudo comprender que había ya perdido la batalla contra la enfermedad.

Las fotografías postmortem fueron durante varios siglos un modo de mantener en la memoria a los seres queridos que habían partido, pero también son evidencia documental de que una persona, adulta o infante, existió y el lugar que ocupó en una familia. La democratización del acceso a las fotografías hizo posible que los retratos mortuorios pudieran incluirse incluso, en álbumes familiares ${ }^{19}$.

Cuando la misión de Grace mantener vivos y sanos a sus hijos fue fallida, fue en la muerte, que Grace 
encontró una nueva realidad, una en la que ella podría disfrutar de la compañía de sus hijos, en su mansión y a plena luz del sol, sin tener que temer más por la vida que ya habían perdido (Foto 13 ).

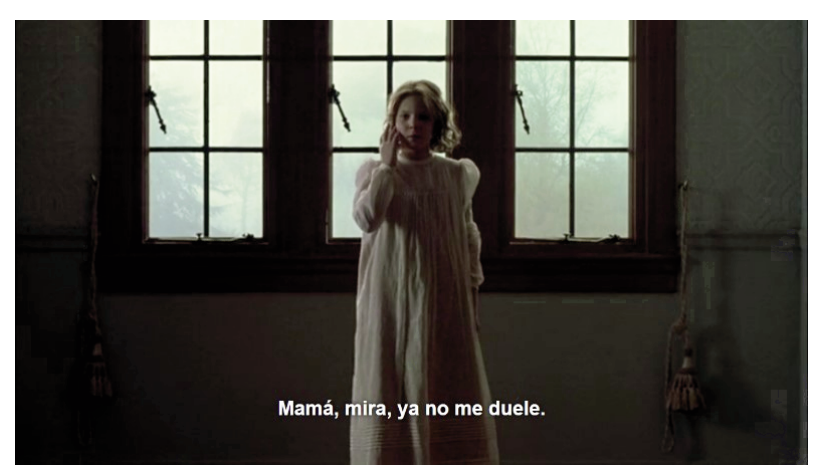

Foto 13. Una nueva realidad.

\section{Conclusión}

A pesar del continuo cuidado y de todas las precauciones que Grace tomaba para evitar la exposición de sus hijos a la luz solar, como pudimos ver, la mortalidad por xeroderma pigmentosa solía ocurrir a corta edad, hasta antes de la segunda mitad del siglo XX y aun con el avance de la ciencia médica, la calidad de vida de los pacientes portadores es aun subóptima. Sin embargo, los descubrimientos con respecto a la etiología de este padecimiento sirven en la actualidad en la prevención mediante la consejería genética de los padres portadores que sin duda reducirá aún más su incidencia.

\section{Referencias}

1. Pérez-Elizondo AD, Pino-Rojas GT, García-Hernández JF. Xeroderma pigmentoso. Breve revisión: de lo molecular a lo clínico. Rev Argent. Dermatol. 2014;95(1):23-8.

2. Camargo R, Choque J, Soledad W, Nikolay J. Xeroderma pigmentoso Rev Bol Ped. 2008; 47(1):16-8

3. Zamarrón A, García M, Del Río M, Larcher F, Juarranz A. Effects of photodynamic therapy on dermal fibroblasts from xeroderma pigmentosum and GorlinGoltz syndrome patients. Oncotarget. 2017;8(44): 77385-99.

4. Hansjorg H, Ernst K, Hermann G, Fritz M. U.S. Patent No. 3,004,896. Washington, DC: U.S. Patent and Trademark Office. 1961.

5. Sollitto RB, Kraemer KA, DiGiovanna JD. Normal vitamin D levels can be maintained despite rigorous photoprotection: six years' experience with xeroderma pigmentosum. J Am Acad Dermatol. 1997;37(6):942-7.

6. Steiger A. Sleep and endocrinology. Journal Inter Med. 2003;254(1):13-22.

7. García R, Aguilar A, Puig P, Solis O, Padilla A. Xeroderma pigmentoso en dos hermanas. Rev Mex Pediatr. 2002;69(4):151-4.

8. Melardo E. El xeroderma pigmentoso en su fase de proliferación cutánea tumoral. Rev Cubana Pediatr. 2012;84(1): 103-16.

9. Díaz-Leonard D, Herrera-Alonoso A, Vigera-Fajardo MN. Xeroderma pigmentoso. Medisur. [Internet]. 2008;6(2):186-9.

10. Instituto Valenciano de Microbiología (IVAMI). Pruebas genéticas: Xeroderma pigmentosum (Xeroderma pigmentosum), genes ERCC2, POLH, XPC, ERCC3 y XPA. Instituto Valenciano de Microbiología [Internet] 2012

11. Weisberg NK, Varghese M. Therapeutic response of a brother and sister with xeroderma pigmentosum to imiquimod $5 \%$ cream. Dermatol Surg. 2002;28(6):518-23.

12. Falcón-Lincheta L, Dorticós-Balea A, Daniel-Simón R, Garbayo-Otaño E. Xeroderma pigmentoso: Síndrome de Sanctis Cacchione, presentación de un caso. Rev Cubana Pediatr. 1998;70(2):113-16.

13. Cordero-Gutiérrez N, Tejeda-Navarro L, Espina-Fleites ED, Membrides-Pérez PP, Álvarez-Donis AM y Cordero Gutiérrez A. Conocimiento de los pacientes con xeroderma pigmentoso sobre su enfermedad y conducta de afrontamiento. Medicentro. 2011;15(2):146-50.

14. Arenas R. Dermatología atlas, diagnóstico y tratamiento. 5ta. Ed. México: Mc Graw Hill; 2013.

15. English J, Swerdlow A. The risk of malignant melanoma, internal malignancy and mortality in xeroderma pigmentosum patients. Br J Dermatol. 1987;117:457-61.

16. Butt FM, Moshi JR, Owibingire S, Chindia ML. Xeroderma pigmentosum: a review and case series. J Craniomaxillofac Surg. 2010;38(7):534-7.

17. Xenoderma Pigmentoso. EcuRed [Internet]. [Consultado el 3 de junio de 2018].

18. Escobar-Vega H, Expósito-Jalturin A, López-Hernández E. Xeroderma pigmentoso de kaposi. presentación de un caso. Rev haban cienc méd [Internet]. 2009; $8(1): 1-4$.

19. Cuarterolo A. La visión del cuerpo en la fotografía mortuoria. Revista Aisthesis. 2017;(35), 51-5.

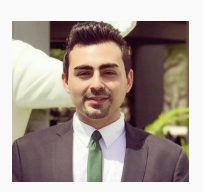

Esteban Aguilar Vargas es Médico Cirujano, actualmente realiza su servicio social en el Centro de Simulación Médica Montagne. Ha sido reconocido como ganador el premio Yucatán de Ciencia Juvenil 2017. Ha realizado presentaciones de sus trabajos de investigación en foros médicos especializados y es autor de cuatro artículos de investigación médica. 